\title{
Lexical decision in a phonologically shallow orthography
}

\author{
G. LUKATELA, D. POPADIĆ, and P. OGNJENOVIĆ \\ University of Belgrade, Belgrade, Yugoslavia
}

and

\author{
M. T. TURVEY \\ University of Connecticut and Haskins Laboratories, New Haven, Connecticut 06510
}

\begin{abstract}
The Serbo-Croatian language is written in two alphabets, Roman and Cyrillic. Both orthographies transcribe the sounds of the language in a regular and straightforward fashion and may, therefore, be referred to as phonologically shallow in contrast to English orthography, which is phonologically deep. Most of the alphabet characters are unique to one alphabet or the other. There are, however, a number of shared characters, some of which receive the same reading and some of which receive a different reading, in the two alphabets. It is possible, therefore, to construct a variety of types of letter strings. Some of these can be read in only one way and can be either a word or nonsense. Other letter strings can be pronounced one way if read as Roman and in a distinctively different way if read as Cyrillic and can be words in both alphabets-but different words; or they can be nonsense in both alphabets or nonsense in one alphabet and a word in the other. In a lexical decision task conducted with bialphabetical readers, it was shown that words that can be read in two different ways are accepted more slowly and with greater error than words that can be read only one way. It was concluded that for the phonologically shallow writing systems of Serbo-Croatian, lexical decision proceeds with reference to the phonology.
\end{abstract}

A case can be made for distinguishing among alphabetic writing systems in terms of the derivational complexity that relates the spelling to the underlying phonological form (Liberman, Liberman, Mattingly, \& Shankweiler, in press). English orthography is the notorious example of a "phonologically deep" writing system; but it is a truly phonographic orthography in spite of its depth because each spelled English word contains strong hints as to its pronunciation. Nevertheless, the opaqueness of the link between English script and phonology is seen by many as a barrier to phonological involvement in fluent reading (Goodman, 1973; Kolers, 1970; Smith, 1971). The argument runs as follows: Given the difficulty of deriving the phonology, readers of English would be considerably better off if they had the option of bypassing the phonology and of relating to their alphabetic orthography much in the same way that the readers of Chinese, say, are thought to relate to their logographic orthography, that is, of proceeding directly from script to meaning. The latter point of view receives some measure of support from analyses that purportedly reveal a closer fit of English

This research was supported in part by NICHD Grant HD08495 to the University of Belgrade and in part by NICHD Grant HD-01994 to Haskins Laboratories. Reprint requests can be sent either to G. Lukatela, Faculty of Electrical Engineering, Bulevar Revolucije 73, Beograd, Yugoslavia, or to M. T. Turvey, Haskins Laboratories, 270 Crown Street, New Haven, Connecticut 06510 . orthography to morphology rather than to phonology (e.g., Chomsky, 1970).

The generally voiced arguments for denying a phonological intermediary in the fluent reading of English have been carefully reviewed by Rozin and Gleitman (1977). Their impression is that these arguments cut both ways and can, ironically, be taken to strengthen rather than to weaken the claim for a principled use of phonology in reading. Additionally, Rozin and Gleitman (1977) point out that it is wiser to interpret the English writing system as a rich mixture of several grains of linguistic representation peppered with arbitrary features (arising from scribal practices, printers' conventions, etc.) rather than as a spelling system that is optimal for any single grain of linguistic representation.

One implication of the last remark is that the reading of English may proceed simultaneously at several grain sizes of linguistic analysis (Rozin \& Gleitman, 1977). It is, therefore, easy to venture that the multiple linguistic analyses afforded by English writing are reason enough for the failure to achieve experimental resolution to the question of a phonological mediary in the mapping from script to meaning. In any given experimental situation, the phonological representation may be obscured by other permissible representations. On the other hand, or additionally, it can be ventured that the failure to resolve the question of phonological mediation is owing to the fact that most of the experimental procedures used to investigate it are not directly relevant 
to its resolution. Coltheart and his colleagues (Coltheart, Davelaar, Jonasson, \& Besner, 1977; Davelaar, Coltheart, Besner, \& Jonasson, 1978) have argued that the only legitimate experimental tasks are those that logically require the use of lexical knowledge. The lexical decision task meets the advocated criterion: Letter strings that are words must be rapidly distinguished from letter strings that are nonwords.

One consistent finding from lexical decision research that is interpreted by some as implicating phonological involvement in the accessing of English lexical items is that it takes an adult reader longer to reject a nonword that sounds exactly like a real word than to reject a nonword that does not sound like any word (Coltheart et al., 1977; Rubenstein, Lewis, \& Rubenstein, 1971). Importantly, however, a cognate observation has proven less reliable, namely, that acceptance latencies are slower for homophonous words than for nonhomophonous words (Rubenstein et al., 1971). When differences in parts of speech and frequency of occurrence are ruled out, words that sound like other words are accepted as rapidly as words that are phonetically dissimilar to other words (Coltheart et al., 1977). In summary, it would appear that phonology mediates the rejection of nonwords but does not mediate the acceptance of words, a conclusion that undercuts the claim that phonology mediates the normal reading of English. In paraphrase of Coltheart et al. (1977), evidence for phonologically mediated lexical access would be more convincing if phonological involvement could be shown in positive lexical decisions.

Although the sought-after evidence has been forthcoming, it has not been without an important qualification. Davelaar et al. (1978) demonstrated that homophony affected lexical decision on words but only when the nonwords, the distractor items, if you wish, were nonhomophonic with lexical items. We see, in short, that phonological involvement in the accessing of English lexical items may well be optional. Apparently, when the strategy of referencing the phonology is less than ideal, as in the case in a lexical decision task in which the nonwords sound like real words, the strategy can be inhibited and other strategies, other grains of linguistic analysis, are given prominence (cf. Davelaar et al., 1978).

The focus of the present paper is a language that is written in a "phonologically shallow" orthography. Serbo-Croatian, the major language of Yugoslavia, is written in two alphabets, Roman and Cyrillic, both of which were constructed in the last century according to the simple rule: "Write as you speak and speak as it is written." Both the Roman and Cyrillic orthographies transcribe the sounds of the Serbo-Croatian language in a regular and straightforward fashion, and there are no (nontrivial) derivation rules to speak of. (Indeed, it is questionable whether the notion of "phonological representation" is befitting the written Serbo-Croatian language. "Phonetic representation" may be sufficient, and more suitable.) $)^{1}$
It seems to us that the generally expressed reasons given against a phonological mediary in the fluent reading of English are not applicable, even in principle, to the fluent reading of Serbo-Croatian (Lukatela \& Turvey, in press). The Serbo-Croatian orthographies are optimal for transcribing the phonology and are transparent in that regard; therefore, no special difficulty is raised for a phonological mediary in the reading of Serbo-Croatian. We might suppose, therefore, that lexical decision on Serbo-Croatian letter strings exhibits a greater or, at least, a more apparent sensitivity to phonology than does lexical decision on English letter strings. Previous research with Serbo-Croatian (Lukatela, Savic, Gligorijerić, Ognjenović, \& Turvey, 1978) might be interpreted as evidence of an obligatory phonological reference in lexical decision, but we must, of necessity, preface a summary of that research by a brief statement of the relation between the two Serbo-Croatian alphabets. (For a more detailed description, see Lukatela, Savić, Ognjenović, \& Turvey, 1978; Lukatela $\&$ Turvey, in press).

The Roman and Cyrillic alphabets map onto the same set of phones but comprise two sets of letters that are, with certain exceptions, mutually exclusive (see Figure 1). Most of the Roman and Cyrillic letters are unique to their respective alphabets. There are, however, a number of letters that the two alphabets have in common. The phonetic interpretation of some of these shared letters is the same whether they are read as Cyrillic or as Roman letters; these are referred to as common letters. Other members of the shared letters have two phonetic interpretations, one in the Roman reading and one in the Cyrillic reading; these are referred to as ambiguous letters. Whatever their category the individual letters of the two alphabets have phonetic

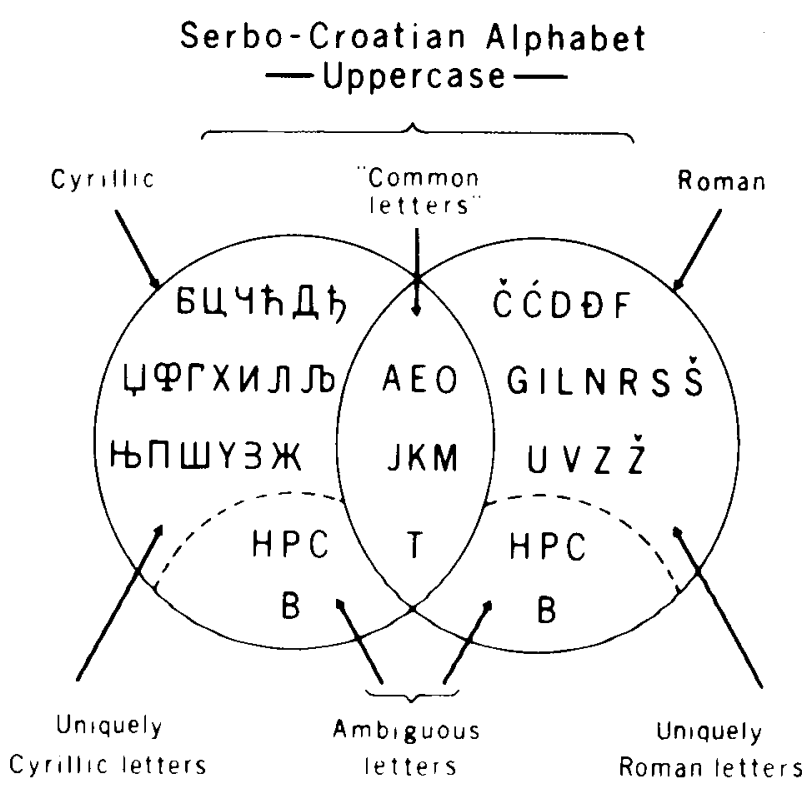

Figure 1. The uppercase characters of the Roman and Cyrillic alphabets of Serbo-Croation. 
interpretations that are virtually invariant over letter contexts. Moreover, all the individual letters in a string of letters, be it a word or nonsense, are pronouncedthere are no letters made silent by context. Finally, but not least in importance, we should note that the two alphabets are used competently by a large portion of the population. This is due, in part, to an educational requirement that both alphabets be taught within the first two grades. The first-taught alphabet is Roman in the western part of Yugoslavia and Cyrillic in the eastern part of Yugoslavia.

Given the nature of and the relation between the two Serbo-Croatian alphabets, it is possible to construct a variety of types of letter strings. A letter string of uniquely Roman letters or of uniquely Cyrillic letters would be read in only one way and could be either a word or nonsense. A letter string composed of the common and ambiguous letters could be pronounced one way if read as Roman and pronounced in a distinctively different way if read as Cyrillic; morever, it could be a word in one alphabet and nonsense in the other, or it could represent two different words, one in one alphabet and one in the other, or it could be nonsense in both alphabets.

We can now summarize our previous research on lexical decision. In three experiments, subjects who could read in both alphabets and who had received their elementary education in eastern Yugoslavia were presented letter strings for lexical decision in the Roman alphabet mode. The requisite mode was determined by instruction and by the selection of letter strings. Letters unique to the Cyrillic alphabet were not used to compose the letter strings, and comparatively few of the letter strings were constructed from the common and ambiguous letters. In short, very few of the presented letter strings could be read in the Cyrillic alphabet mode. It was demonstrated that lexical decision was slowed when a letter string could be read in two ways (i.e., could be read in either the assigned Roman alphabet or the nonassigned Cyrillic alphabet), but only if it were the case that the letter string was in fact a word in (at least) one of the alphabets. A nonsense string of letters readable in both alphabets was rejected no more slowly than a nonsense string constructed from the set of letters unique to the Roman alphabet.

By arranging matters so as to make the use of a phonological code punitive in accessing English lexical items, Davelaar et al. (1978) found that phonological access was abandoned or that, if it was used, its consequences were ignored. In the Lukatela, Savic, Gligorijević, Ognjenović, and Turvey (1978) experiments, matters were arranged so that only one phonological code, that relating to the Roman alphabet, was necessary for the successful performance of the task. But our subjects, apparently, were unable to suppress the alternative (and uncalled for) phonological code, that relating to the Cyrillic alphabet.

That a familiar item may be encoded automatically, in the related senses of not requiring conscious attention and of not being optional, is central to certain contemporary views of attention and pattern recognition, of which that of Posner and Snyder (1975) is a notable example.

In the experiment reported in the present paper, bialphabetical subjects made lexical decisions on letter strings that were composed from the unique letters of both alphabets as well as from the common and ambiguous letters. That is to say, in contrast with the previous experiments (Lukatela, Savić, Gligorijević, Ognjenović, \& Turvey, 1978) no alphabet bias was imposed upon the subjects by the selection of letter strings; nor was it imposed by instruction. Subjects simply had to identify whether or not a letter string, be it Cyrillic or Roman, represented a word in the Serbo-Croatian language. On the evidence of our previous research, it would be nonoptimal to access the lexicon via the phonology if that means of access necessarily entailed both the Roman and the Cyrillic phonological codes. Far more prudent would be a strategy in which access to the lexicon was restricted to the graphemic route (see . Coltheart et al., 1977; Meyer, Schavaneveldt, \& Ruddy, 1974) or, at least, a strategy in which, of the two routes, only the graphemic was heeded in final decision making. It proves to be the case, however, that, consonant with the earlier observations on biased bialphabetical subjects, unbiased bialphabetical subjects, under the conditions of the present experiment, exhibit an inability to suppress the phonological coding of Serbo-Croatian letter strings. As before, words that can be read in two different ways are accepted more slowly and with greater error than words that can be read only one way.

\section{METHOD}

Subjects

The participants in the experiments were 48 students from the Department of Psychology at the University of Belgrade. The majority of the 48 students had received their elementary education in eastern Yugoslavia, and all of them had participated previously in reaction time experiments.

\section{Materials and Design}

Letraset black uppercase Roman and Cyrillic letters (Helvetia Light, 12 point) were used to prepare the letter strings. A string of three to six letters arranged horizontally at the center of a $35-\mathrm{mm}$ slide represented a word or a nonword in the SerboCroatian language. There are no frequency counts for SerboCroatian words comparable to the Thorndike-Lorge or KuceraFrancis counts for English words. As with our previous experiments, all words were selected from the middle range of word frequencies for Serbian elementary school children, as reported by Lukic $(1970)$. The words readable in only one alphabet were chosen so that their mean frequencies of occurrence were as close as possible to those of the words readable in both alphabets. While it is possible that words selected from the Lukic table of frequencies may not be either as close together or as far apart on a table of frequencies of adult usage, it is most unlikely that, where differences in frequency arise, those differences are in terms of the single-alphabet/double-alphabet distinction. The point we wish to underscore is that there is little 
Table 1

Types of Letter Strings in the Roman and Cyrillic Alphabets

\begin{tabular}{|c|c|c|c|c|c|c|}
\hline \multirow{2}{*}{$\begin{array}{l}\text { Type of } \\
\text { letter } \\
\text { string } \\
\text { (LS) }\end{array}$} & \multicolumn{2}{|c|}{ Lexical entry (L) } & \multicolumn{2}{|c|}{$\begin{array}{l}\text { Phonological } \\
\text { representation (P) }\end{array}$} & \multirow[t]{2}{*}{$\begin{array}{l}\text { Symbolic } \\
\text { representation }\end{array}$} & \multirow{2}{*}{$\begin{array}{c}\text { Is it } \\
\text { a word? } \\
\text { (in Roman } \\
\text { or in } \\
\text { Cyrillic) }\end{array}$} \\
\hline & $\begin{array}{c}\text { In } \\
\text { Roman } \\
\left(L_{R}\right) ?\end{array}$ & $\begin{array}{l}\text { In } \\
\text { Cyrillic } \\
\left(\mathrm{L}_{\mathrm{C}}\right) ?\end{array}$ & $\begin{array}{c}\text { In } \\
\text { Roman } \\
\left(\mathrm{P}_{\mathrm{R}}\right) ?\end{array}$ & $\begin{array}{c}\text { In } \\
\text { Cyrillic } \\
\left(\mathrm{P}_{\mathrm{C}}\right) ?\end{array}$ & & \\
\hline LS1 & Yes & No & Yes & No & & Yes \\
\hline LS1a & No & Yes & No & Yes & & Yes \\
\hline LS3 & Yes & Yes & Yes & Yes & & Yes \\
\hline LS4 & Yes & No & Yes & Yes & & Yes \\
\hline LS 5 & Yes & Yes & Yes & Yes & & Yes \\
\hline LS6 & No & Yes & Yes & Yes & & Yes \\
\hline LS 7 & No & No & Yes & Yes & & No \\
\hline LS 8 & No & No & Yes & No & & No \\
\hline LS8a & No & No & No & Yes & & No \\
\hline LS9 & No & No & Yes & Yes & & No \\
\hline
\end{tabular}


reason to believe that in adult usage the bialphabetic words of the present experiment occur less frequently than the singlealphabet words of the present experiment.

In addition to the frequency constraint, word selection was restricted to words that did not contain rare consonant clusters. That restriction was also applied to the nonword letter strings that were the same length and the same number of syllables as the words. All in all, there were 10 different types of letter strings (LS); these are shown in Table 1 , together with the correct lexical decision for each type. (The reason for the odd labeling of the letter strings is to maintain consistency with the table of letter strings given previously in Lukatela, Savic, Gligorijevic, Ognjenovic, \& Turvey, 1978; the present table includes letter strings that are uniquely Cyrillic, which the previous table did not.) Table 1 is largely self-explanatory, but one useful point of clarification is that LS5 and LS9 are constructed solely from the common letters (see Figure 1) and are therefore read the same way and, if words, mean the same thing in the Roman and in the Cyrillic alphabets. In total, 144 letter strings were constructed, of which half were words (12 tokens for each of the six types of word letter string) and half were nonwords (18 tokens for each of the four types of nonword letter string).

The 144 letter strings seen by a subject were presented in four blocks. In each block the letter strings of each type were presented in a pseudorandom order. The sequence of blocks was balanced across subjects, and the same string of letters was never judged more than once by a subject.

\section{Procedure}

The subject was seated at a three-channel tachistoscope (Scientific Prototype, Model GB). The subject was instructed to focus on the fixation point in the center of a preexposure field that was present at all times except during presentation of a letter string. Each letter string was preceded by an auditory warning signal. The onset of a letter string triggered an electronic counter that was stopped when the subject pressed one of two buttons on a response panel in front of him. Both hands were used. Both thumbs were placed on a telegraph key close to the subject, and both forefingers were placed on another telegraph key 2 in. further away. The subject depressed the closer key (thumbs) if the letter string was a nonword and the other further key (forefingers) if the letter string was a word. Regardless of the subject's response time, a letter string was always automatically replaced after $750 \mathrm{msec}$ by the preexposure field.

\section{RESULTS}

The decision latency of each subject to each type of letter string was the basic datum for analysis. Those responses that exceeded $1,300 \mathrm{msec}$ were considered errors ("slow responses"), together with "regular" errors, namely, those responses in which the wrong decision was made. A lower criterion of $250 \mathrm{msec}$ was also applied to rule out excessively fast responses, but no responses of this rapidity occurred in the experiment. For purposes of analysis, the latency of a subject's incorrect response was replaced by his or her average latency for that particular type of letter string. Figure 2 gives the decision time and error data for the 10 types of letter strings. The analysis of variance conducted on the data included three factors: The type of letter string was treated as a fixed factor, with words and subjects treated as random factors. The relevant comparisons follow.

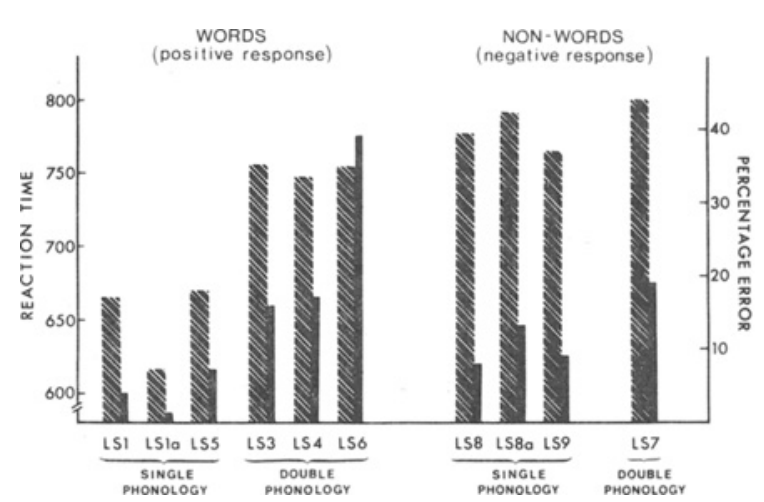

Figure 2. Latencies and errors (too slow and wrong) for lexical decision to 10 types of letter strings. Wide striped bars represent latencies, and thin solid bars represent errors.

First, we consider the analysis of positive decision times. Decision latency was significantly slower (1) for letter strings of Type LS4 than for letter strings of Type LS1 $\left[F^{\prime}(1,26)=11.72, p<.01\right]$, (2) for letter strings of Type LS6 than for letter strings of Type LS1 a $\left[F^{\prime}(1,25)=41.55, p<.001\right]$, (3) for letter strings of Type LS3 than for letter strings of Type LS5 $\left[F^{\prime}(1,27)=\right.$ $8.90, \mathrm{p}<.01]$.

With regard to the total errors (both slow and regular) on positive response trials, a Wilcoxon signed-ranks test was conducted on the proportions of correct responses for each comparison of interest. Significant differences were found between errors to LS1 and to those of LS4 $(p<.001)$, between errors to LSla and those to LS6 $(p<.001)$, and between errors to LS3 and those to LS5 $(\mathrm{p}<.001)$. In summary, when a word was readable in both alphabets, lexical decision was slowed and errors were increased.

Let us now consider the decision latencies for negative responses. Decision latency was not significantly slower $(p<.05)$ for letter strings of Type LS7 than for letter strings of Types LS8, LS8a, and LS9. However, in view of the greater number of slow responses incurred on letter strings of Type LS7 (by a Wilcoxon signedranks test, the difference in slow responses between LS7 and LS8 was significant at the .001 level), the data were reanalyzed ignoring the cutoff criterion for slow responses. That is to say, a second analysis was conducted in which a slow response was not replaced by the subject's mean latency but was included in the analysis as a raw datum. On this analysis, decision time for LS7 was significantly slower than decision times for LS8 $(p<.05)$ and LS9 $(p<.05)$, but not slower than decision time to LS8a $(p<.05)$. In short, there is reason to believe that a letter string's affiliation to both alphabets retards negative decision time, a result that is contrary to the observation made in our previous research on bialphabetical lexical decision. 


\section{DISCUSSION}

Can we take the present experiment as showing that the phonologic form of Serbo-Croatian letter strings contributes significantly to lexical decision? The general sense of the argument for a nonphonologic route to the lexicon is that the reader uses some aspect of the visual appearance of a letter string to directly access its lexical representation.

One fairly representative account of lexical decision is given by Meyer and Ruddy (Note 1). They interpret the relation between the phonological and visual routes to the lexicon as one of competition. A phonologically constrained search of the lexicon is conducted simultaneously with a visually constrained search, and sometimes it is the former search and sometimes it is the latter search that first accesses the target lexical item. When the access is through the phonology and the language is English (or, presumably, an orthographic cognate), a spelling recheck is conducted to insure against judging homophones as words.

For sake of argument, let us suppose that in the present experiment either the direct visual route was more rapid than the phonological route-so that lexical entries were detected more often than not by reference to the word's visual appearance-or the phonologic route was suppressed on grounds of inefficiency. If either supposition were correct, then our subjects should have accepted words readable in both alphabets as rapidly as they accepted words readable in just one alphabet. Given a Serbo-Croatian word such as $\mathrm{CAH}$, which is read differently in the two alphabets but is a word (dream) only in Cryillic, a lexical search conducted in reference to its visual appearance should have been no slower than the lexical search conducted in reference to the visual appearance of $60 \mathrm{I}$, an unequivocal letter string meaning pain. We are reminded, however, that words such as $\mathrm{CAH}$ were responded to more slowly and with considerably more error.

Clearly, an appeal solely to the mechanism of direct visual access will be insufficient to account for the present data. Nevertheless, an appeal to some kind of visually related mechanism might work; that is, the data may still be accommodated by a nonphonological interpretation. Suppose that ambiguous letters are specially tagged in memory, and suppose, further, that the realization of an ambiguous character through graphemic analysis always eventuates in a slowing of visually guided search. On both rational and empirical grounds, however, the latter proposal seems unlikely. Presumably, the reason for slowing lexical search is that the circumstances demand that gieater than usual care be taken to avoid erroneous responses; thus, pursuant to each unsuccessful visual match, a check might be made on its validity. But the fact that a character is ambiguous in reference to sound cannot be important to the matching process qua visual matching. Character ambiguity in phonetic interpretation cannot increase the possibility of matching error in the domain of visual feature matching, and the detection of ambiguous characters in a letter string, therefore, cannot be proposed as a sensible reason for slowing visual search. An (unreported) observation from our previous research is of importance in this regard. In Experiment 1 of the Lukatela, Savić, Gligorijević, Ognjenović, and Turvey (1978) experiments, the letter strings of Type LS1 sometimes included an ambiguous character. If the presence of ambiguous characters slows lexical search, then the letter strings that included ambiguous characters should have been accepted with the long latencies characteristic of LS3, LS4, LS6, which they were not, and not with the short latencies of LS1, which they were.

Experimental data also permit us to reject a similar argument that takes the common letters as its focus. In the present experiment, for example, letter strings composed of common letters (LS5) were associated with a response pattern (latency and error) that marks them as more closely related to letter strings of Types LS1 and LS1a than to letter strings of Types LS3, LS4, and LS6. There is, however, a more profound reason for rejecting the idea that the presence of common letters slows lexical decision-the simple fact that most vowels are common to the two alphabets, and, therefore, any letter string consistent with the language must contain common letters.

It remains to be seen whether or not other visual coding arguments can be made that differ substantially from the ones given here. For the present, we take the inadequacy of the above graphically based interpretations of the present data to be an indictment against any purely visual account and, indirectly, as support for the inclusion of a phonologically based interpretation. In summary, we claim that the present data are evidence for a phonological mediary in lexical decision. Let us proceed to examine the consequence of this claim and the kind of mechanism needed to explain how phonological bivalence retards lexical decision.

Insofar as the task before the subject was one that, in theory, could have been performed most efficiently by ignoring the phonetic form of the letter strings, it can be argued that phonologic coding is not optional in lexical decision for readers of Serbo-Croatian, or, more conservatively, that it is not a form of coding that the native reader of Serbo-Croatian can easily avoid. Perhaps it is here that a distinction of potential significance can be drawn between the reading of a phonologically deep orthography such as that of English and a phonologically shallow orthography such as that of Serbo-Croatian: Acquiring a phonologically deep orthography encourages the development of coding options and a sensitivity to linguistic contexts in which individual coding strategies are optimal; by comparison, acquiring a phonologically shallow orthography encourages neither the development of coding options or (axiomatically) a sensitivity 
to the situations for which they are most appropriate.

It is not our intention in this last remark to claim that access to the lexicon is, for the reader of Serbo-Croatian, exclusively phonological. Rather we intend to express the notion that the cost of automatizing ways of accessing the Serbo-Croatian lexicon other than through the use of the general, transparent, and productive relation between letter patterns and phonetic form probably outweighs the benefits. A mechanism for directly accessing lexical items from some aspects of the visual appearance of letter strings implies a formidable amount of learning about specific stimuli (see Baron, 1977; Brooks, 1977). The long-term benefit of such learning, if successful, is that lexical access might be expedited (Coltheart et al., 1977). Nevertheless, we are presuming that such extensive learning has to be well motivated, and our feeling is that, in this regard, there is little to spur the Yugoslavian reader, given the spellingto-sound regularity of the Serbo-Croatian orthographies and the efficient and economical reading mechanisms that it makes possible. In terms of a contrast that others (Baron \& Strawson, 1976) have found useful, we would expect that fluent readers of Serbo-Croatian would be disproportionately Phoenician (roughly, treat letter strings as alphabetic) in comparison with fluent readers of English who might divide more evenly on the Phoenician-Chinese (roughly, treat letter strings as logographic) dichotomy.

In seeking an account of the effect of bialphabetic letter structure on lexical decision, we pursue a model of lexical decision recently formulated by Coltheart and his colleagues (Coltheart et al., 1977; Davelaar et al., 1978). Their model is essentially an extension of Morton's $(1969,1970)$ logogen model, and it can be considered as representative of a different class of models from that represented by the Meyer and Ruddy (Note 1) interpretation and described above.

Each word has its own logogen, understood as a memory device that accepts various kinds of information specifying the nature of a letter string. The requisite information is to be found in the letter string itself, in its visual appearance and its phonological structure, and in the context in which the letter string occurs. Each logogen has a certain threshold that is inversely related, over the long term, to the frequency of usage of the word and, over the short term, to the recency of its usage. On this conception, lexical access is equated with the accumulation by a logogen of information to the threshold level. And "search" is equated with the simultaneous accumulation in a number of different logogens of the information that they can accept. In the logogen view, lexical search is parallel in contrast to the serial search that characterizes the model of Meyer and Ruddy (1973) (and that of Forster, 1976).

It is reasonably apparent how the logogen view accommodates positive lexical decision, but it is not obvious how it might accommodate the decision that a letter string does not have a lexical entry. For what would reliably justify a "no" response? Surely, it cannot be the fact that at the moment of the decision no logogen has yet reached threshold because, with further delay, a logogen may well do so. To remedy this inadequacy of the logogen account, Coltheart et al. (1977) have proposed that in a lexical decision task the subject makes use of a temporal criterion, a deadline, which is tied to the onset of the individual letter string and is extended as a direct function of the overall level of activation of the logogens following onset. When the (variable) deadline has expired, the subject responds "no."

The two important parameters of the modified logogen model are the logogen threshold and the decision deadline. When lexical decision is slowed by a letter string's affiliation with both Serbo-Croatian alphabets, which of these two parameters bears the responsibility? The arguments of Coltheart et al. (1977) highlight the greater flexibility of the deadline parameter, so let us consider that first. The fact that a letter string of Types LS3, LS4, LS6, and LS7 is phonologically bivalent might mean that the number of logogens such a letter string excites exceeds the number excited by a letter string readable in only one alphabet. This means, on the modified logogen view, that the deadline must be later for phonologically bivalent letter strings. Consider the comparison between LS7, on the one hand, and LS8 and LS8a, on the other. If phonological bivalence extends the deadline, then rejection latencies should be slower for LS7. We recall that the number of responses exceeding our cutoff of $1,300 \mathrm{msec}$, responses designated as errors, were significantly greater for LS7 than for LS8 and LS8a and, further, that when the latency data were reanalyzed without the cutoff criterion, responses to LS7 were significantly slower than responses to LS8 but not those to LS8a. These results are compatible with an extended deadline interpretation of phonological bivalence. We should note, however, that our previous research (Lukatela, Savić, Gligorijević, Ognjenović, \& Turvey, 1978) failed to demonstrate an effect of phonological bivalence on negative responses. As remarked at the outset, the present experiment is distinguished from the preceding ones in that no alphabet bias was imposed upon the subjects, and that, in and of itself, may be sufficient reason for the different pattern of results for negative responses. Importantly, however, it is only in this one result that the present and previous experiments differ; in all other outcomes they are virtually identical.

But if it can be agreed that phonological bivalence extends the deadline, how would that fact account for the pattern of results for positive decision? It would be nonsense to assume that positive decisions are delayed until the deadline is reached. While such an assumption correctly predicts slower latencies for words read differently in the two alphabets vs. words 
readable in only one alphabet, it incorrectly predicts that positive and negative response latencies should be the same. Perhaps we need to consider the possibility that phonological bivalence also influences the threshold parameter. If phonological bivalence raises logogen thresholds across the board, then we would expect positive decisions to be slowed. With the threshold raised more time would be needed to accumulate the evidence sufficient to trigger a logogen.

To effect a raising of threshold that is contingent on a letter string's readability in both alphabets requires a mechanism that monitors the consequences of the graphemic-to-phonemic mapping and adds a constant to the threshold value of each individual logogen on the occasion that two distinct phonologic interpretations arise for a given letter string. The nature of this mechanism is admittedly ad hoc, but then so is the mechanism proposed by Coltheart et al. (1977) to modulate the decision deadline according to the excitation level of the lexicon. But the ad hoc feature of the threshold-raising mechanism is a lesser source of discomfort than is the absence of a rationalization for it.

It would be prudent to raise the thresholds of lexical entries in conditions of stimulation and context that are likely to exaggerate the false alarm rate. Can we argue that the condition of phonological bivalence is such a condition? When interpreting the negative response data, we assumed that when a letter string could receive two distinct phonological descriptions more logogens would be excited than when the letter string was phonologically singular; we assumed, in short, that phonological bivalence delays the deadline. In general, a direct relation between the level of excitation of the internal lexicon and the deadline for negative responses is rational: The more logogens excited, the more likely it is that the proper response is "yes"; if the lexicon is relatively quiescent, the proper response is more likely to be "no." Here, then, is our dilemma. We have said that when a letter string can receive two different phonological interpretations the deadline is extended to guard against misses. The very reasonableness of this statement is argument against the claim that when a letter string can receive two different phonological interpretations, the thresholds are raised to guard against false alarms. We cannot have our cake and eat it too. The benefits of delaying the deadline would be erased by raising the thresholds.

Perhaps we should credit phonological bivalence not with the raising of thresholds but with a slowing down in the process that determines the phonological structure of a letter string. If that process were slowed when a bialphabetic letter string is presented, then the accumulation of phonologic evidence would be retarded and thresholds would be reached at later intervals. This interpretation of the influence of phonological bivalence on positive responses requires no new mechanisms and no ad hoc adjudicating on the benefits and costs of this or that strategy. The question, however, is whether this interpretation does indeed accommodate the data, particularly the pattern of errors. A rough analysis suggests that it does.

Slow responses and incorrect responses were considerably more frequent for words readable in both alphabets than for words readable in just one alphabet. One way to account for the incorrect responses is to suppose that on some occasions the decision deadline was exceeded before a threshold was reached. The slower the determination of the phonological structure of a letter string, the lower the rate at which the level of lexical excitation rises and the longer the period before the deadline undergoes appreciable extension. Consequently, a substantial change in the decision deadline will, on some occasions, not occur rapidly enough to offset the slowed accumulation of phonological evidence, and a "no" response will be emitted.

There is another mechanism that might be proposed that would similarly produce the desired consequence of slowing the rate at which evidence in individual logogens accumulates when the target letter string is readable in two ways. The locus of this alternative mechanism is within the logogen system itself rather than prefatory to it. Specifically, the mechanism is a parallel search procedure of limited power. The operating characteristic of such a search mechanism is that the more representations excited in parallel, the slower the rate at which any individual representation approaches its threshold (Anderson, 1976).

The foregoing considerations of the mechanisms underlying lexical decision are not by any means exhaustive, nor are they intended to be so. At best, they sketch out possible approaches to the data of the present experiment and of those reported previously (Lukatela, Savić, Gligorijević, Ognjenović, and Turvey, 1978). We should not, however, let the difficulty of ascribing a mechanism obscure the conclusion to which the present data point: For the phonologically shallow writing systems of Serbo-Croatian, lexical decision proceeds with reference to the phonology.

\section{REFERENCE NOTE}

1. Meyer, D. E., \& Ruddy, M. Lexical memory retrieval based on graphemic and phonemic representations of printed words. Paper presented at the annual meeting of the Psychonomic Society, St. Louis, November 1973.

\section{REFERENCES}

Anderson, J. R. Language, memory, and thought. Hillsdale, N.J: Erlbaum, 1976.

BARON, J. Mechanisms for pronouncing printed words: Use and acquisition. In D. LaBerge \& S. J. Samuels (Eds.), Basic processes in reading: Perception and comprehension. Hillsdale, N.J: Erlbaum, 1977. 
Baron, J., \& Strawson, C. Use of orthographic and wordspecific knowledge in reading words aloud. Journal of Experimental Psychology: Human Perception and Performance, 1976, 2, 386-393.

Brooks, L. R. Visual pattern in fluent word identification. In A. Reber \& D. Scarborough (Eds.), Towards a psychology of reading. Hillsdale, N.J: Erlbaum, 1977.

Cномsкy, N. Phonology and reading. In H. Levin \& J. P. Williams (Eds.), Basic studies on reading. New York: Basic Books, 1970.

Coltheart, M., Davelaar, E., Jonasson, T., \& Besner, D. Access to the internal lexicon. In S. Dornic (Ed.), Attention and performance VI. London: Academic Press, 1977.

Davelaar, E., Coltheart, M., Besner, D., \& Jonasson, J. T. Phonological recoding and lexical access. Memory \& Cognition, $1978,6,391-402$.

Forster, K. I. Accessing the mental lexicon. In R. J. Wales \& E. C. T. Walker (Eds.), New approaches to language mechanisms. Amsterdam: North-Holland, 1976.

Goodman, K. The 13th easy way to make learning to read difficult: A reaction to Gleitman and Rozin. Reading Research Quarterly, 1973, 8, 484-493.

Kole RS, P. Three stages of reading. In H. Levin \& J. P. Williams (Eds.), Basic studies on reading. New York: Basic Books, 1970.

Liberman, I., Liberman, A., Mattingly, I. G., \& ShAN KWEILER, D. Orthography and the beginning reader. In J. Kavanaugh \& R. Venesky (Eds.), Orthography, reading and dyslexia. Baltimore, Md: University Park Press, in press.

Lukatela, G., Savić, M., Gligorijević, B., Ognjenović, P., \& Turvey, M. T. Bi-alphabetical lexical decision. Language and Speech, 1978, 21, 142-165.

Lukatela, G., Savić, M., Ognjenović, P., \& Turvey, M. T. On the relation between processing the Roman and the Cyrillic alphabets: A preliminary analysis with bi-alphabetical readers. Language and Speech, 1978, 21, 113-141.

Lukatela, G., \& Turvey, M. T. Some experiments on the Roman and Cyrillic alphabets of Serbo-Croatian. In J. Kavanaugh \& R. Venezky (Eds.), Orthography, reading and dyslexia. Baltimore, Md: University Park Press, in press.

LUKIC, V. [Active written vocabulary of pupils at the elementary school age]. Belgrade: Zavod za Izdavanje Udzbenika SR Srbije, 1970.

Meyer, D. E., Schvaneveldt, R. W., \& Ruddy, M. G. Func- tions of graphemic and phonemic codes in visual word recognition. Memory \& Cognition, 1974, 2, 309-321.

Morton, J. Interaction of information in word recognition. Psychological Review, 1969, 76, 165-178.

Morton, J. A functional model for memory. In D. A. Norman (Ed.), Models of human memory. New York: Academic Press, 1970.

Posner, M. I., \& SNyder, C. R. Attention and cognitive control. In $\mathrm{R}$. L. Solso (Ed.), Information processing and cognition. Hillsdale, N.J: Erlbaum, 1975.

Rozin, P., \& Gleitman, L. R. The structure and acquisition of reading II. The reading process and the acquisition of the alphabetic principle. In A. Reber \& D. Scarborough (Eds.), Towards a psychology of reading. Hillsdale, N.J: Erlbaum, 1977.

Rubenstein, H. R., Lewis, S. S., \& Rubenstein, M. A. Evidence for phonemic recoding in visual word recognition. Journal of Verbal Learning and Verbal Behavior, 1971, 10, 645-657.

Smith, F. Understanding reading. New York: Holl, Rinehart, \& Winston, 1971 .

\section{NOTE}

1. It can be argued that for English the representational medium of relevance to the internal lexicon and its access is probably phonological. Thus, any word in the English lexicon is conveyed as a sequence of systematic phonemes divided into its constituent morphemes. For example, "heal" and "health" have the morphophonemic representations /hêl/ and /hël $+\theta /$. These representations are distinct from their phonetic counterparts; "heal" and "health" are realized approximately as [hiyl] and [hel $\theta$ ]. In the phonetic representation of an English word the underlying morphophonemic form is often disguised and the morphophonemic boundaries absent (see Liberman et al., in press). In contrast with English, we claim here that the phonetic representation of Serbo-Croatian words is virtually indistinguishable from the phonological representation.

(Received for publication April 30, 1979; revision accepted October $8,1979$. 